\title{
The management of posterior epistaxis in the United Kingdom, a national survey*
}

A. Mowat, P. Meakin, S. Anastasiadou, R. Bidaye, S. Anari

Birmingham Heartlands Hospital, United Kingdom
Rhinology Online, Vol 5: 19 - 22, 2022

http://doi.org/10.4193/RHINOL/21.056

*Received for publication:

November 27, 2021

Accepted: January 21, 2021

Published: January 30, 2022

\begin{abstract}
Background: Posterior bleeds account for $5 \%$ of epistaxis. The patient cohort is often elderly and has significant co-morbidities. Such cases have been managed historically with urinary catheters, held in place with umbilical clips. Recently bespoke, double balloon, posterior packs have been utilised. The treatments remain in clinical equipoise with no gold standard or clear national guideline.
\end{abstract}

Methodology: A ten question survey was sent out through www.surveymonkey.com. Attempts were made to contact all Trusts in the United Kingdom via the ENT on call service. A comparison of treatment costs was made.

Results: 112 responses have been received. 54\% of respondents reported a preference for bespoke posterior pack insertion, only $12 \%$ preferred catheters. Twice as many respondents have seen complications from urinary catheters: $14 \%$ vs $29 \%$. The availability of posterior packs is inconsistent: $30 \%$ of respondents were not aware of the packs or reported them unavailable in their hospital.

Conclusions: This survey provides the first comparison of the techniques in the United Kingdom. Bespoke packs have a lower complication rate and are preferred by ENT clinicians on the front line of patient care. We recommend that all UK trusts should stock posterior packs which should be used as first line treatment for cases of posterior epistaxis.

Key words: epistaxis, nasal surgical procedures, nose, public health

Posterior bleeds account for $5 \%$ of epistaxis ${ }^{(1)}$. The patient cohort is often elderly and has significant co-morbidities ${ }^{(2)}$. Cases are clinically identified, when bleeding is predominantly seen in the oropharynx rather than in the nostrils, or when bleeds do not respond to anterior nasal packing.

ENT UK guidelines currently advise the use of posterior nasal packs or catheters in cases of profuse bleeding in which anterior non-dissolvable nasal packs have been unsuccessful in stemming bleeding. Or in low volume bleeds which has been refractory to dissolvable packs and nasal cautery ${ }^{(3)}$.

Historically refractory posterior epistaxis has been managed with urinary catheters, held in place with umbilical clips ${ }^{(4)}$. This method is technically difficult, and carries the risk of nasal alar necrosis, although this risk is reduced with the effective use of ribbon gauze ${ }^{(5)}$. Urinary catheters are not licensed for this use $\mathrm{e}^{(6)}$ (Figure 1).

Over the last ten years bespoke, double balloon, posterior packs have been utilised under the same circumstances ${ }^{(7)}$. The treatments remain in clinical equipoise with no gold standard.

We distributed a ten-question survey through www.surveymonkey.com. The survey had a mean completion time of two minutes. All ENT on call services were contacted. In the England, the NHS is subdivided into the organisational unit of a trust. These are responsible for the financing and delivery of healthcare. In Scotland and Wales, Healthcare Boards provide the same facility. 112 responses from 46 of the 215 NHS trusts were received between 01/01/2020 and 01/06/2020. 


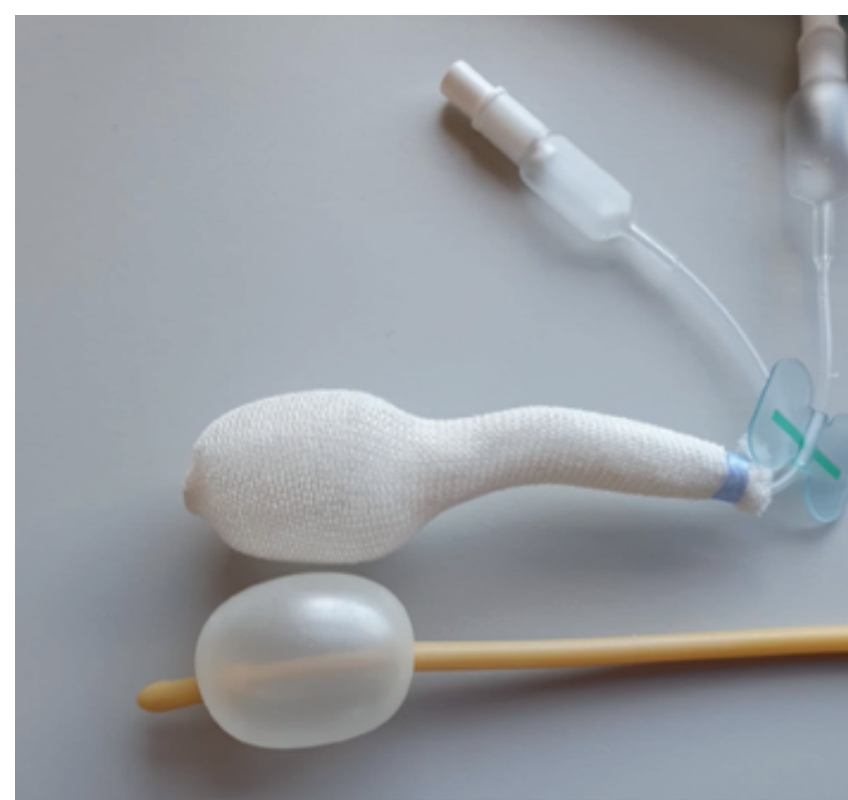

Figure 1. Posterior pack (above), urinary catheter (below).

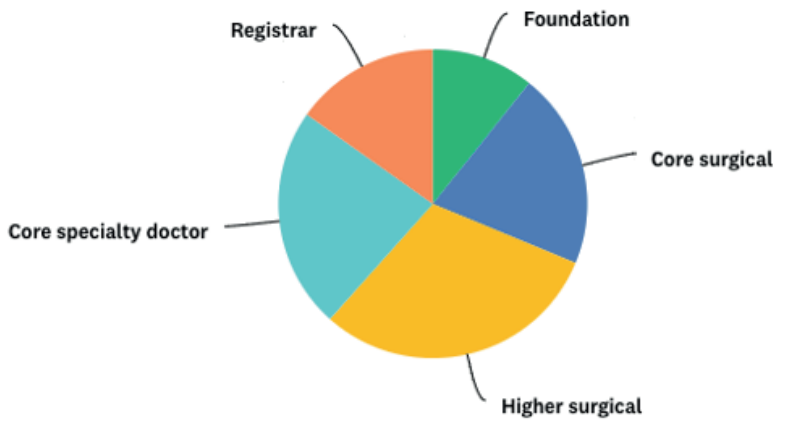

Figure 2.'What is your level of training?'

Many ENT on call services represent amalgamations of two or more trusts, hence the survey results can be taken as representative of over half the on call services in the United Kingdom. All English regions were represented, as well as Scotland, Wales and Northern Ireland.

A wide range of responders replied. 34 were within higher surgical training, with a further 17 practising as a registrar in a non-training capacity. The remainder were practising at a senior house officer level, either as a foundation, or core trainee or non-trainee. All were involved in delivering the acute ENT on call service.

$40 \%$ of responders had greater than three years of experience in ENT (Figure 2). 9\% of responders had no time within ENT as their home specialty, which reflects the cross covering arrangements common within UK hospitals (Figure 3).

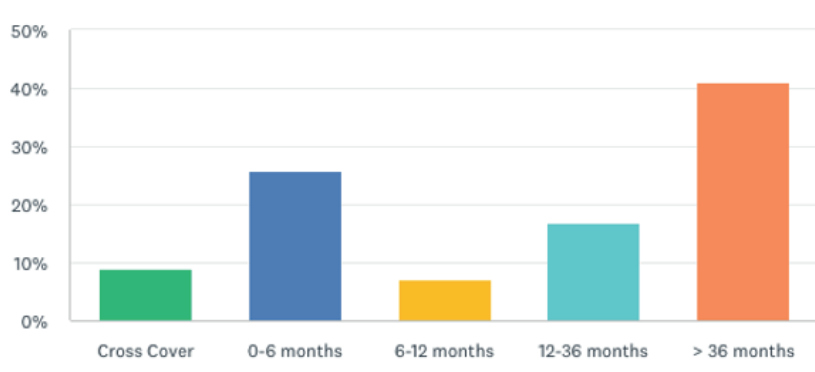

Figure 3. 'How much ENT experience do you have?'

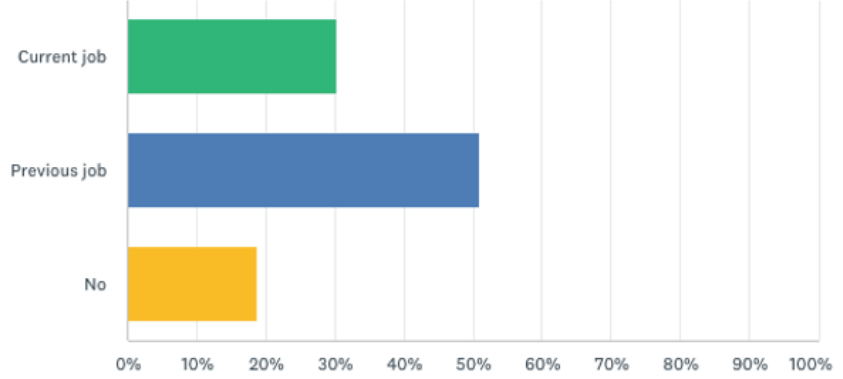

Figure 4. 'Have you personally been given any training or induction on the management of posterior epistaxis with either posterior packs or catheters?'

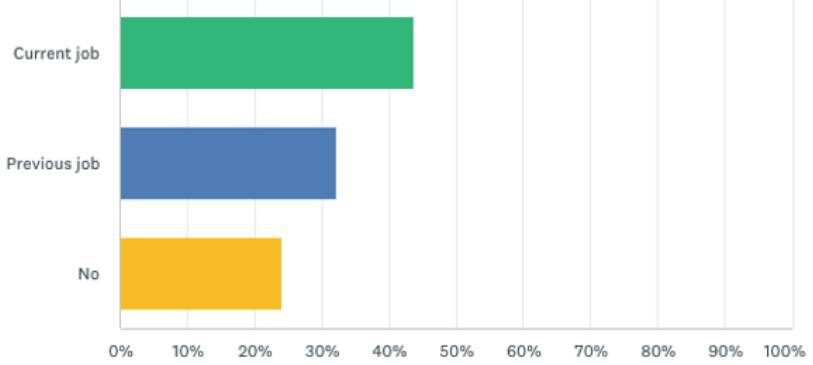

Figure 5. 'Have you managed any patients with posterior epistaxis?'

Question four focused on the training received by clinicians in the management of posterior epistaxis. This is inconsistent. $30 \%$ of respondents had received some form of induction into management of posterior epistaxis on their present job. A further $51 \%$ had received training on a previous job. $19 \%$ of on call ENT doctors were working without any formal training in the use of either packs or catheters (Figure 4).

The majority of on call ENT doctors have managed posterior epistaxis in either their current (49\%) or previous job (36\%). However, $26 \%$ of those responding had never managed posterior epistaxis with either technique (Figure 5).

Questions 6 \& 7 focus on the respective availability of posterior packs and urinary catheters. The availability of posterior packs was inconsistent (Figure 6). $41 \%$ of respondents reported packs being carried in the on call bag, which represents good practice. 


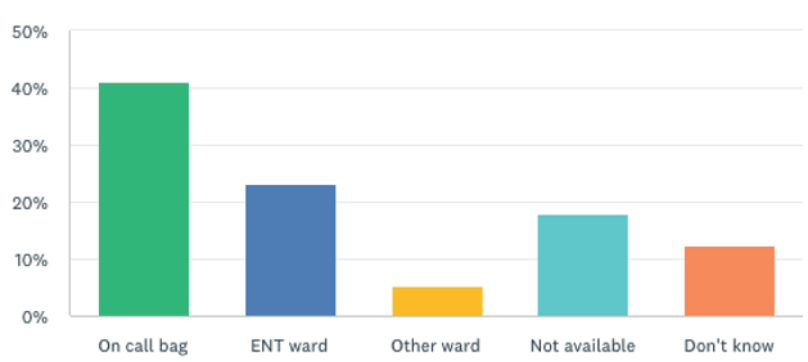

Figure 6. 'What is the availability of purpose made posterior balloon packs in your trust?'

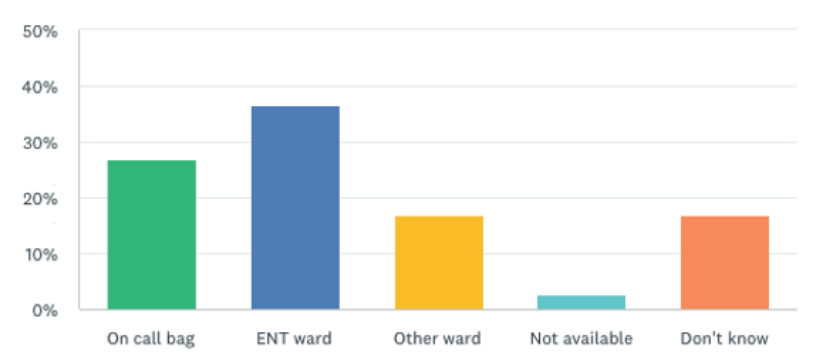

Figure 7.'What is the availability of urinary catheters and umbilical clips?'

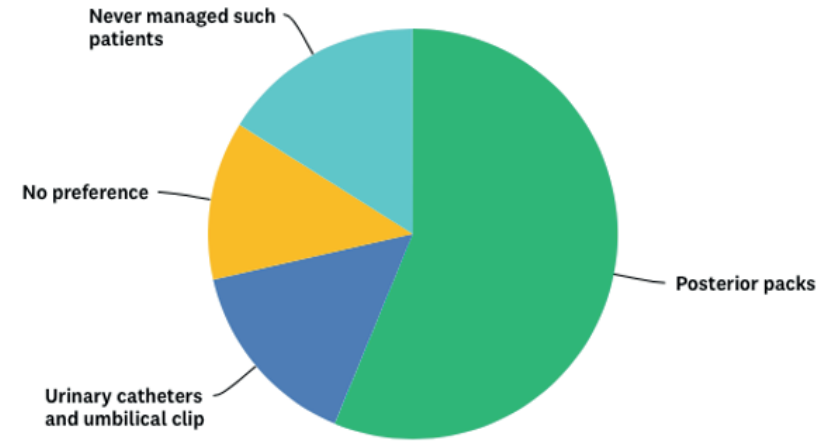

Figure 8. 'Do you have a preference in the management of posterior epistaxis?'

Another 23\% reported the packs to be available on the ENT ward or another ward (5\%). However, over $30 \%$ of respondents reported packs to be unavailable in their trust (18\%) or did not know if they were stocked (13\%).

The reported availability of posterior packs correlates well with reports from the major supplier of posterior packs who have reported that only $40 \%$ of active accounts are purchasing posterior packs. The availability of urinary catheters is more ubiquitous than posterior packs (Figure 7). Only three respondents reported them unavailable in their trust. A lower proportion of trusts reported them to be carried in the on call bag (27\%). More commonly they were retrieved from the ENT ward (37\%).

Question 8 focused on the clinicians' preference on the management (Figure 8 ). The results showed that respondents

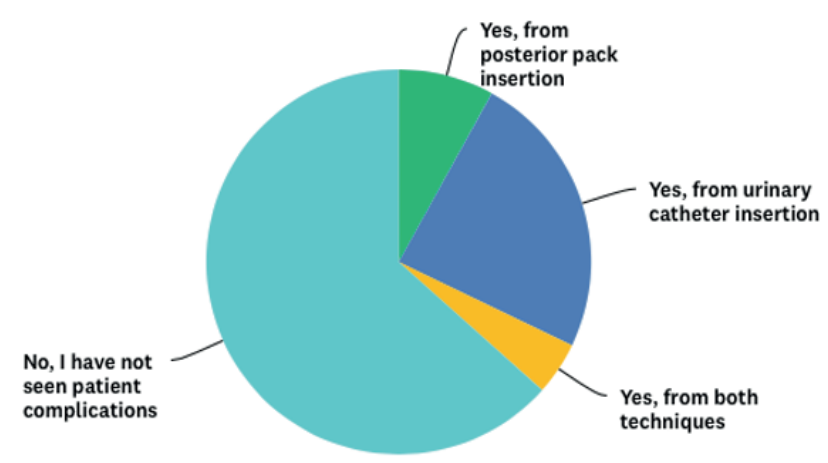

Figure 9. 'Have you seen complications from either technique?'

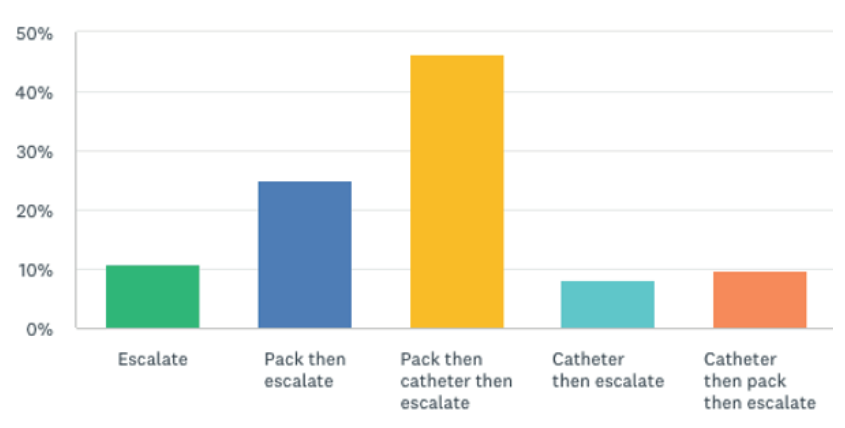

Figure 10. 'What is your treatment hierarchy for the management of posterior epistaxis?'

overwhelmingly preferred to use posterior packs, (54\% vs $12 \%)$. This displays their superior usability compared to catheters. The remainder of responders had no preference on the issue or had never managed such patients.

Question 9 focused on complications encountered (Figure 9). Reassuringly a majority of responders had not seen complications with either technique (63\%). However, twice as many respondents have seen complications from urinary catheters over posterior packs ( $29 \%$ vs $14 \%$ ). A minority of respondents reported having seen complications using both techniques (4\%).

The final question sought to analyse the treatment hierarchy used by on call clinicians in managing patients with posterior epistaxis (Figure 10). The results showed a wide variety of practice in such circumstances indicative of the current lack of national directive. $11 \%$ of respondents would escalate such a case without attempting to stem the bleeding with either a pack or a catheter.

$70 \%$ of respondents would use utilise a posterior pack in the first instance, before escalating (25\%) or using a catheter as a second line, and then escalating (45\%). However, $17 \%$ of respondents would use a catheter as first line, before escalating (8\%), or packing then escalating (9\%). The reflects the absence of training 
in the management of posterior epistaxis described in question 4 , and the lack of a national guideline dictating a management hierarchy.

We went on to perform a cost comparison of the two treatment modalities. The most prominent brand of posterior packs retails for a unit cost of $£ 29.16$. This is greater than that of a urinary catheter and an umbilical clip. The clip alone can carry a unit cost of $£ 25.00$, depending on the brand use. Furthermore, frequently a urinary catheter in the posterior choanae has to be simultaneously combined with a single balloon rapid rhino to prevent anterior haemorrhage. Anterior packs have a unit cost of $£ 11.98$ from the same supplier. Hence, double balloon packs can be considered better than cost equivalent.

\section{Conclusion}

This survey provides most comprehensive comparison of the techniques for the management of posterior epistaxis in the United Kingdom. Double balloon posterior packs have a lower complication rate and are preferred by clinicians. However, their utilisation by different trusts remains inconsistent. We recommend that all UK hospitals stock posterior packs which should be considered first line treatment in such cases. The survey argues for a paradigm shift in the management of posterior epistaxis, and ending the use of urinary catheters for this role. Anecdotally, this is already the case in much of continental Europe.

\section{Authorship contribution}

AJM: Data analysis and contribution, Manuscript preparation and revisions, Project conception. PM, SA, RB: Data collection. SA: Project conception and design, manuscript revisions.

\section{Acknowledgments}

None.

\section{Funding}

No sources of funding to declare.

\section{Ethics approval and consent to participate}

No approval or consent needed.

\section{Consent for publication}

Not applicable.

\section{Availability of data and materials}

On request, all data and study protocol can be made available.

\section{Conflict of interest}

The authors declare no conflict of interest.

\section{References}

1. Viducich RA, Blanda MP, Gerson LW Posterior epistaxis: clinical features and acute complications. Ann. Emergen Med. 1995; 25(5), 592-596.

2. Kucik CJ, Clenney TL. Management of epistaxis. Am Fam Physician. 2005; 71(2) 305-311.

3. https://www.entuk.org/rhinology-andfacial-plastics-guidelines

4. Hartley C, Axon PR. The Foley catheter in epistaxis management-a scientific appraisal. J Laryngol Otol.1994; 108(5), 399-402.

5. Thomas L, Karagama YG, Watson C. Avoiding alar necrosis with post-nasa packs. J Laryngol Otol. 2005;119(9), 727-728.

6. Pellard S, Boyce J, Ingrams DR. Consent and the use of Foley catheters in epistaxis. Laryngol Otol. 2005;119(10), 822-824.

7. Fatakia A, Winters R, Amedee RG. Epistaxis: a common problem. Ochsner J. 2010;10(3) 176-178.

\section{A. Mowat}

Birmingham Heartlands Hospital, United Kingdom

E-Mail: andrewmowat@live.com 